\title{
Estimation of protein intake using urinary urea nitrogen in patients with early-stage liver cirrhosis
}

\author{
Yohei Kida · Hiroki Ueda $\cdot$ Hiroto Tanaka • \\ Masakazu Ichinose
}

Received: 18 July 2007 / Accepted: 19 July 2007/Published online: 22 September 2007

(C) Asian Pacific Association for the Study of the Liver 2007

\begin{abstract}
Purpose Evaluation of protein intake of patients with liver cirrhosis (LC) would facilitate optimal nutritional support. However, it has never been done on the basis of urinary urea nitrogen (UUN). The aim of this study, therefore, is to determine the usefulness of the estimated protein intake (EPI) based on UUN in patients with LC.

Methods A total of 42 patients with early-stage LC were enrolled in this study. The actual protein intake (API) was defined as the dietary protein intake $(1.0 \mathrm{~g} / \mathrm{kg} / \mathrm{d})$ plus supplementation of any enteral diets containing branchedchain amino acids (BCAA). We calculated EPI from UUN using the formula [UUN $(\mathrm{g} / \mathrm{d})+0.031 \times$ body weight $(\mathrm{kg})] \times 0.625$. We examined the correlation between EPI and API, the EPI/API ratio (EAR), and the correction based on the results.

Results A significant positive correlation was found between API and EPI $(r=0.703, p<0.001)$. The EAR in all patients was $0.84 \pm 0.11$. EPI times 1.2 was the correction needed to adjust EAR to 1 . The corrected EPI was correlated with API $(r=0.704, p<0.001)$. The corrected EAR of all 42 patients was $1.01 \pm 0.13$.

Conclusion In conclusion, for patients with early-stage LC, an EPI calculated from UUN may be a useful tool for optimal nutritional support. The corrected EPI would be very useful for improved monitoring of early-stage LC.
\end{abstract}

Keywords Urinary urea nitrogen - Liver cirrhosis · Protein intake

Y. Kida $(\bigotimes) \cdot$ H. Ueda $\cdot$ H. Tanaka $\cdot$ M. Ichinose

The Third Department of Internal Medicine, Wakayama Medical University, 811-1 Kimiidera, Wakayama City 641-8509, Japan e-mail: yofactory@yahoo.co.jp

\section{Introduction}

Protein and energy malnutrition is common in patients with liver cirrhosis (LC). It is also a significant predictor of survival [1-3] and is a putative predictor for outcomes after liver transplantation in such patients [4]. Enteral nutrition guidelines for liver disease were reported in 2006 by the European Society for Clinical Nutrition and Metabolism (ESPEN) [5]. In general, the restriction of dietary protein has long been recognized as an effective treatment for patients with hepatic encephalopathy [5-8]. To evaluate the protein intake of patients with LC, therefore, optimal nutritional support should be facilitated. However, such a method has never been employed in these patients. On the other hand, in patients with chronic renal failure (CRF), the protein intake based on the urinary urea nitrogen (UUN) is used for the estimation of the dietary protein intake, and was found to be useful for nutritional education [9-11].

This study was carried out to determine whether protein intake could be estimated from UUN in patients with earlystage LC.

\section{Methods}

Subjects

A total of 42 patients with LC at the Third Department of Internal Medicine, Wakayama Medical University Hospital, and its two affiliated hospitals were enrolled in this study. The study protocol was approved by the institutional review board of those hospitals. All patients agreed to cooperate in the nutrition therapy study. Written informed consent to participate in this study was obtained from all patients. 
Oral ingestion of meals was possible in all patients. The following patients were excluded from our study: patients who did not eat an adequate amount and did not cooperate in the nutrition therapy and urine test; 24-h creatinine clearance (24Ccr) was less than $50 \mathrm{ml} / \mathrm{min}$; hepatoma, ascites, or peripheral edema; Child-Pugh grade either B or $\mathrm{C}$; consciousness and orientation not alert and good; and blood urea nitrogen-creatinine ratio 10 or less.

The characteristics of patients are summarized in Table 1 . The patients, aged $51-80$ years (average $65.3 \pm 7.1$ ), consisted of 33 males and 9 females. The etiologies of LC were alcohol consumption in six cases, autoimmune hepatitis in three cases, hepatitis B virus in five cases, and hepatitis $C$ virus in 28 cases. All patients were Child-Pugh grade A. Fifteen patients $(35.7 \%)$ had esophageal varices. Three patients (7.1\%) had hepatic encephalopathy in the past. When enrolled in the study, the serum albumin level of all patients exceeded $3.5 \mathrm{~g} / \mathrm{dL}$. Eight patients had been administered branchedchain amino acids (BCAA) orally because of a decrease in the serum albumin level $(<3.5 \mathrm{~g} / \mathrm{dL})$ in the past. The average laboratory data of the patients were as follows: UUN $6.13 \pm 1.06 \mathrm{~g} / \mathrm{d}$, serum albumin $3.81 \pm 0.21 \mathrm{~g} / \mathrm{dL}$, total bilirubin $0.80 \pm 0.23 \mathrm{mg} / \mathrm{dL}$, prothrombin time $84.5 \pm 13.5 \%$, and platelet count $7.44 \pm 1.60 \times 10^{4} / \mathrm{mm}^{3}$.

Definition of actual and estimated protein intake

The actual protein intake (API) was defined as the total protein intake from hospital meals $(1.0 \mathrm{~g} / \mathrm{kg} / \mathrm{d})$ plus supplements

Table 1 Characteristics of the patients

\begin{tabular}{ll}
\hline Characteristics & \\
\hline Number of patients & 42 \\
Gender $(\mathrm{M} / \mathrm{F})$ & $33 / 9$ \\
Age $(\mathrm{yr})$ & $65.3 \pm 7.11$ \\
Body weight $(\mathrm{kg})$ & $56.3 \pm 7.58$ \\
Urinary urea nitrogen $(\mathrm{g} / \mathrm{d})$ & $6.13 \pm 1.06$ \\
Etiology (ALD/AIH/HBV/HCV) & $6 / 3 / 5 / 28$ \\
Serum albumin $(\mathrm{g} / \mathrm{dL})$ & $3.81 \pm 0.21$ \\
Total bilirubin $(\mathrm{mg} / \mathrm{dL})$ & $0.80 \pm 0.23$ \\
Platelet count $\left(\times 10^{4} / \mathrm{mm}^{3}\right)$ & $7.44 \pm 1.60$ \\
Child-Pugh grade $(\mathrm{A} / \mathrm{B} / \mathrm{C})$ & $42 / 0 / 0$ \\
Presence of varices & $15(35.7 \%)$ \\
Presence of hepatoma & $0(0 \%)$ \\
Hepatic coma (post history) & $3(7.1 \%)$ \\
Ascites (absent/slight/moderate/severe) & $42 / 0 / 0 / 0$ \\
Peripheral edema (absent/slight/moderate/severe) & $42 / 0 / 0 / 0$ \\
\hline
\end{tabular}

$*_{ \pm}$values are mean \pm standard deviation containing BCAA. The goal of protein intake for inpatients at the hospitals was set as $1.0 \mathrm{~g} / \mathrm{kg} / \mathrm{d}$.

In the hospitals involved in this clinical study, the amount of protein contained in each meal is $10 \mathrm{~g}$. If the body weight of a patient is $40 \mathrm{~kg}$, we assumed that the amount of protein intake should be $40 \mathrm{~g} / \mathrm{d}$, and for a patient of $52 \mathrm{~kg}$, the protein intake should be $52 \mathrm{~g} / \mathrm{d}$. The amount of protein intake, however, was assumed to be $50 \mathrm{~g} / \mathrm{d}$ according to the amount of protein intake in the calculation. The BCAA supplements that we prescribed were Aminoleban EN containing $13.5 \mathrm{~g}$ protein/sachet (Otsuka Pharmaceutical Co., Ltd., Tokyo, Japan) and Livact containing $4 \mathrm{~g}$ protein/sachet (Ajinomoto Pharma Co., Ltd., Tokyo, Japan).

In the first 11 patients with early-stage cirrhosis, the 24$\mathrm{h}$ UUN was measured on days 3, 7, and 10 after admission to observe the changes in UUN and to examine the changes in UUN when meals containing a fixed amount of protein were given. These 11 patients, aged 55-77 years (average $64.9 \pm 6.3$ ), were all males, and the etiology of LC was hepatitis $\mathrm{C}$ virus infection. The patients were all ChildPugh grade A. Four patients $(36.4 \%)$ had esophageal varices. No patients $(0 \%)$ had hepatic encephalopathy in the past. The average laboratory data of the patients were as follows: serum albumin $3.82 \pm 0.14 \mathrm{~g} / \mathrm{dL}$, total bilirubin $0.75 \pm 0.18 \mathrm{mg} / \mathrm{dL}$, prothrombin time $86.4 \pm 11.9 \%$, and platelet count $(6.99 \pm 1.60) \times 10^{4} / \mathrm{mm}^{3}$. No significant differences were found in the characteristic and baseline laboratory data between these 11 patients and the other 31 patients.

We measured the 24-h UUN (g/d) and body weight of all patients on day 7 after admission.

The estimated protein intake (EPI) was calculated using the following equation:

$$
\begin{gathered}
\mathrm{EPI}=[\mathrm{UUN}(\mathrm{g} / \mathrm{d})+0.031 \times \text { body weight }(\mathrm{kg})] \\
\times 0.625+\text { urine protein }(\mathrm{g} / \mathrm{d})
\end{gathered}
$$

[12]. We calculated the EPI/API ratio (EAR) from the EPI and API.

We examined the correlation between API and EPI as well as EAR. In addition, we examined the correction according to the results.

Statistical methods

The results shown are mean \pm standard deviation (SD). We used the Spearman correlation coefficient by rank test for statistical analysis, and the Mann-Whitney $U$ tests, with a $p<0.05$ considered to be significant. 


\section{Results}

Change in UUN after taking hospital meals

The UUN values on days 3, 7, and 10 after admission of each subject are shown in Table 2. The UUN of each subject did not change much. The average UUN on days 3 , 7 , and 10 after admission were $6.15 \pm 0.56,6.23 \pm 0.50$, and $6.17 \pm 0.49 \mathrm{~g} / \mathrm{d}$, respectively, as shown in Fig. 1. No significant difference was seen among the three groups. These results showed that the UUN level did not change after taking hospital meals in patients with early-stage LC patients.

\section{Correlation between EPI and API}

For all patients, a significant positive correlation was found between EPI and API, as shown in Fig. 2A $(n=42$, $r=0.703, p<0.001)$.

\section{EPI/API ratio}

The EAR of all the patients was $0.84 \pm 0.11$, as shown in Fig. 2B.

Correction of EPI based on the results of EAR

The correction was examined according to the results of EAR. To adjust the EAR (which was approximately 0.84) to 1 , the corrected EPI was defined as follows.

Table 2 Twenty-four-hour urinary urea nitrogen (g/d) individual UUN on the $3,7,10$ day post-admission

\begin{tabular}{llll}
\hline & Day 3 & Day 7 & Day 10 \\
\hline Case 1 & 6.12 & 6.33 & 6.22 \\
Case 2 & 5.88 & 5.98 & 6.04 \\
Case 3 & 6.55 & 6.66 & 6.46 \\
Case 4 & 6.66 & 6.55 & 6.46 \\
Case 5 & 6.04 & 5.98 & 5.88 \\
Case 6 & 6.44 & 6.25 & 6.34 \\
Case 7 & 6.46 & 6.44 & 6.24 \\
Case 8 & 5.68 & 5.99 & 5.88 \\
Case 9 & 7.04 & 7.22 & 7.22 \\
Case 10 & 5.88 & 5.98 & 5.90 \\
Case 11 & 4.98 & 5.24 & 5.28 \\
\hline
\end{tabular}

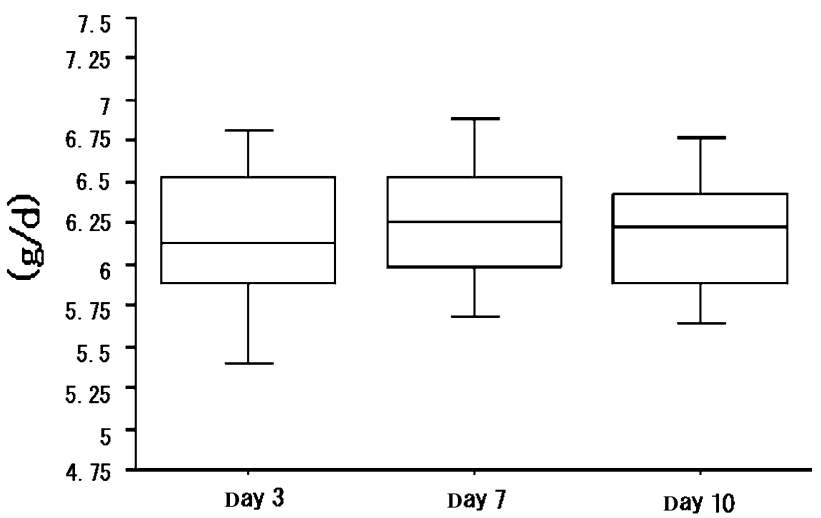

Fig. 1 Average 24-h urinary urea nitrogen on days 3, 7, and 10 after admission $(6.15 \pm 0.56,6.23 \pm 0.50$, and $6.17 \pm 0.49 \mathrm{~g} / \mathrm{d}$, respectively). No significant difference was seen among the three groups

$$
\begin{aligned}
\text { Corrected EPI }=\{ & {[\mathrm{UUN}(\mathrm{g} / \mathrm{d})+0.031 \times \text { body weight }(\mathrm{kg})] } \\
& \times 0.625+\text { urine protein }(\mathrm{g} / \mathrm{d})\} \\
& \times 1.2 .(\text { because } 1 / 0.84=1.19 .)
\end{aligned}
$$
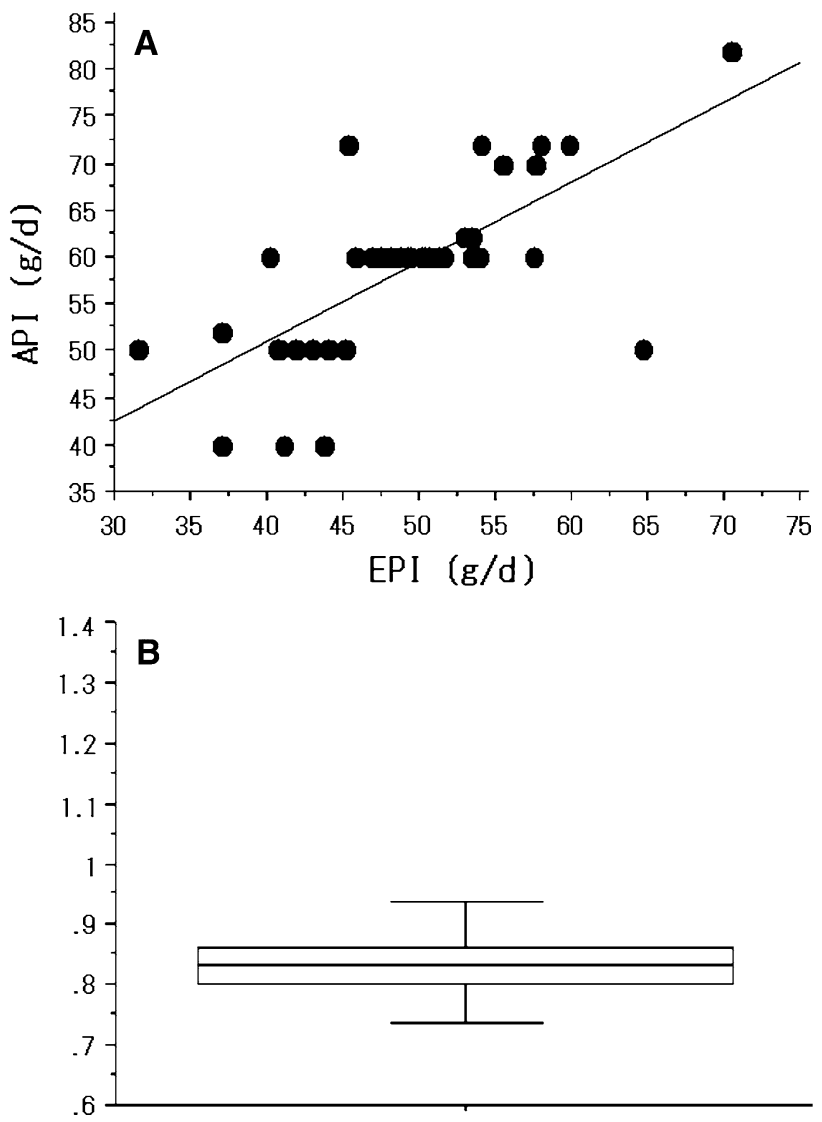

Fig. 2 The correlation between EPI and API, and the EPI/API ratio (EAR), for all patients. A significant positive correlation was found between EPI and API $(n=42, r=0.703, p<0.001)(\mathrm{A})$. The EAR was $0.84 \pm 0.11(\mathrm{~B})$ 

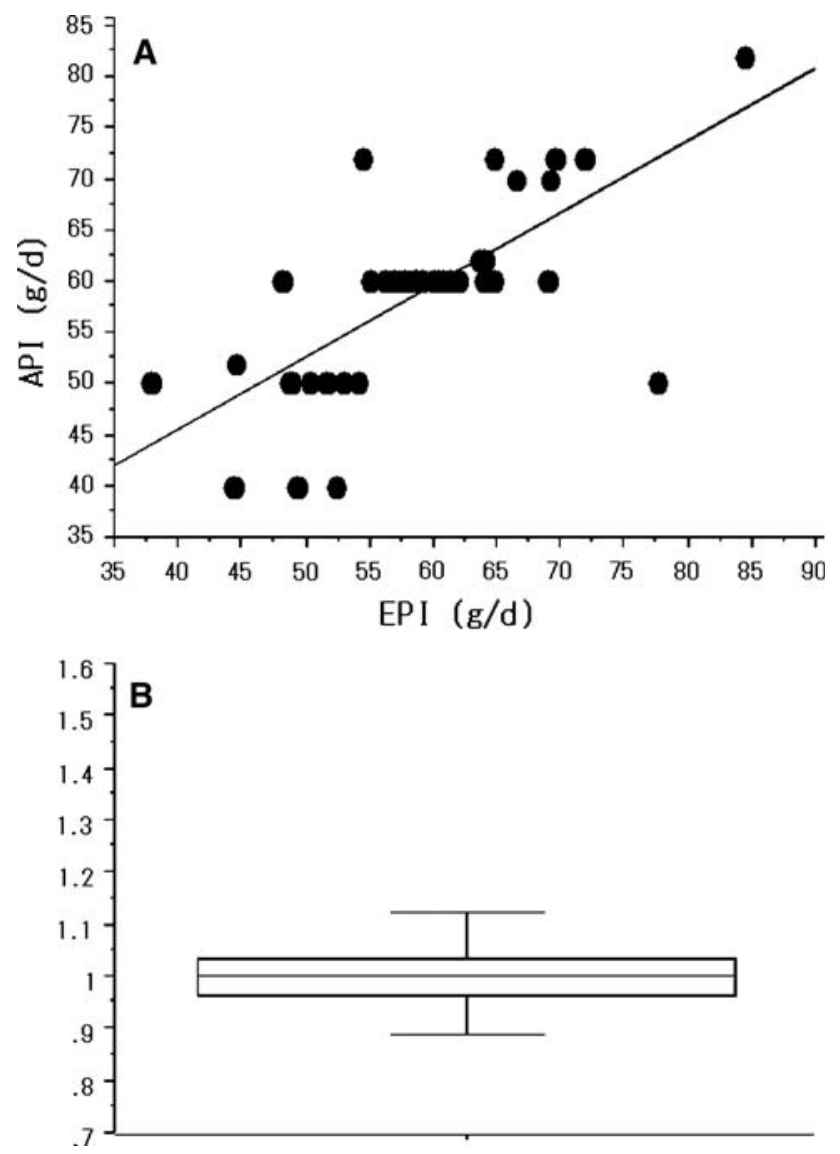

Fig. 3 The correlation between the corrected EPI and API and the EPI/API ratio (EAR) for all patients. A significant positive correlation was found between the corrected EPI and API. The corrected EPI was correlated with API $(n=42, r=0.704, p<0.001)(\mathbf{A})$. The corrected EAR was $1.01 \pm 0.13(\mathbf{B})$

For all patients, a significant positive correlation was found between the corrected EPI and API, which is shown in Fig. 3A ( $n=42, r=0.704, p<0.001)$.

The corrected EAR of the patients was $1.01 \pm 0.13$, as shown in Fig. 3B. The corrected EPI did not influence the correlation, and the EAR could be adjusted to approximately 1 .

\section{Discussion}

We have shown that the EPI could be a useful tool for patients with early-stage LC. The corrected EPI reflected the protein intake of the cirrhosis patients accurately. Our study is the first to validate that EPI can be calculated from UUN for patients with early-stage LC.

API was defined as the total protein intake from hospital meals plus that of the supplement containing BCAA. Evaluation of protein intake in outpatients is very difficult. Actually, dieticians estimate quantity of protein intake from patient interviews and recordings of meal contents by patients. However, the most serious problem of patient interviews and recordings is uncertainty of information. On the other hand, the meal for inpatients is prepared in the hospital and is based on a calculation of the various nutritients. Unless an inpatient eats between meals, the amount of protein intake from a hospital diet can be known. The amount of protein intake from the supplement containing BCAA can also be calculated. Therefore, the amount of protein intake both from hospital meals and the supplement is the actual protein intake in our patients.

In 1985, Maroni et al. proposed that the estimated nitrogen intake could be determined from the UUN. They suggested a method for monitoring dietary compliance in treating patients with CRF. Urea nitrogen appearance $(U)$, calculated as the sum of UUN plus the variation in the body urea pool (using changes in serum urea nitrogen and either the ${ }^{14} \mathrm{C}$ urea space or $60 \%$ body weight), was correlated with nitrogen intake. Total nonurea nitrogen (NUN) excretion and its components did not correlate with dietary nitrogen. NUN averaged $31.3 \pm 2.1 \mathrm{mg} \mathrm{N} / \mathrm{kg} / \mathrm{d}$ and was not different between the two groups or in patients in neutral compared to those in mildly negative or positive nitrogen balance. Nitrogen balance calculated using estimated $U$ and $31 \mathrm{mg} \mathrm{N} / \mathrm{kg} / \mathrm{d}$ was indistinguishable statistically from measured nitrogen balance. Thus, $U$ varies directly with dietary protein intake and can be estimated using urinary urea nitrogen, serum urea nitrogen, and body weight. Total nitrogen excretion can be estimated accurately as $U+31 \mathrm{mg} \mathrm{N} / \mathrm{kg} / \mathrm{d}$. From the estimated total nitrogen excretion, dietary compliance of CRF patients in approximately neutral nitrogen balance could be assessed. Furthermore, if nitrogen intake were known, nitrogen balance could be estimated [12]. Since records of renal function were kept, we included them in our calculations for each patient.

The urinary system is the major excretion route that ensures nitrogen balance both in healthy individuals and in patients with diseased livers. Actually, UUN does have a good correlation with the protein catabolism of the body, and theoretically it will correlate well with the protein intake only if the nitrogen balance is stable.

First, we recorded the UUN for early-stage LC patients under a fixed diet, and found that the excreted nitrogen was stable. From these results, we concluded that there would be no difficulty in validating the EPI for the cirrhosis patients. There was little influence of stress or illness in our patients, because their cirrhosis was at an early stage.

We found a significant positive correlation between EPI and API. It seemed reasonable that patients with LC also could benefit from a determination of the EPI, which is generally used for nutrition therapy in patients with CRF. 
The EAR suggested that EPI was lower than API. This was considered to result from a dysfunction of the urea cycle in patients with LC and from the influence of drugs. Generally, $80 \%$ of the urea nitrogen is excreted in urine. In addition, it is excreted in the feces, the skin, and sweat [13]. The urea cycle function is decreased in patients with LC. Therefore, since UUN tends to decrease, there is a possibility that EPI would also be lower. In our study, we were able to use an EPI for the cirrhosis patients by correcting the EPI reported by Maroni et al.

To apply EPI for outpatients, there are several factors to be considered. For example, because accumulating urine samples through 24-h periods can be burdensome, especially for old people, a reasonable and easy method should be found.

In this study, we did not examine patients with hepatocellular carcinoma and patients of Child-Pugh grades B and $\mathrm{C}$, because cachexia exists in the former and the body weight is influenced by ascites in the latter. These limitations should be examined in a future study.

BCAA is prescribed for some of our patients. Although its use is controversial, BCAA is prescribed for cirrhosis patients in Japan, its use is still controversial. Although some reports have been shown the effects and benefits of longterm nutrition therapy using supplementation with BCAA for patients with LC. BCAA has been reported to be helpful in preventing events related to cirrhosis [14-17], nutrition status [9, 18-20], leg cramps [10], and overall quality of life [11]. The role of BCAA needs to be studied further.

The correlation at a single time point was considered to validate the EPI as an estimate of API in this study. It will be necessary to fulfill additional requirements to confirm the validity of this method, such as the reproducibility and sensitivity to change in dose of API. A longitudinal study will be necessary to complete the validation, in addition to follow-up surveys.

\section{Conclusion}

In conclusion, for patients with early-stage LC, an EPI derived from UUN may be a useful tool for nutritional support. And the corrected EPI would greatly improve the accuracy with which early-stage LC is monitored.

Acknowledgments We thank Brent Bell for reading the manuscript.

\section{References}

1. Alberino F, Gatta A, Amodio P, et al. Nutrition and survival in patients with liver cirrhosis. Nutrition 2001;17:445-50.
2. Tajika M, Kato M, Mohri H, et al. Prognostic value of energy metabolism in patients with liver cirrhosis. Nutrition 2002; 18:229-34.

3. Moriwaki H, Miwa Y, Tajika M, et al. Branched-chain amino acids as a protein- and energy-source in liver cirrhosis. Biochem Biophys Res Commum 2004;313:405-9.

4. Selberg O, Bottcher J, Tusch G, et al. Identification of high- and low-risk patients before liver transplantation: a prospective cohort study of nutritional and metabolic in 150 patients. Hepatology 1997;25:652-7.

5. Plauth M, Carbé E, Riggio O, et al. ESPEN guidelines on enteral nutrition: liver disease. Clin Nutr 2006;25:285-94.

6. Friedman LS. Cirrhosis liver, biliary tract, \& pancreas. In: Tierney LM, McPhee SJ, Paradakis MA, editors. 2006 Current medical diagnosis \& treatment. 45th ed. New York: McGraw-Hill; 2005. p. $668-74$.

7. Chung RT, Podolsky DK. Hepatic encephalopathy cirrhosis and its complication disorders of the gastrointestinal system. In: Kasper DL, Braunwald E, Fauci AS, Hauser SL, Longo DL, Jameson JL, editors. Harrison's principles of internal medicine. 16th ed. New York: McGraw-Hill; 2005. p. 1867-9.

8. Riordan SM, Williams R. Treatment of hepatic encephalopathy. N Engl J Med 1997;337:473-9.

9. Okamoto M, Sakaida I, Tsuchiya M. Effect of a late evening snack on the blood glucose level and energy metabolism in patients with liver cirrhosis. Hepatol Res 2003;27:45-50.

10. Sako K, Imamura Y, Nishimata H. Branched-chain amino acids supplements in the late evening decrease the frequency of muscle cramps with advanced hepatic cirrhosis. Hepatol Res 2003; 26:327-9.

11. Kawamura N, Nakajima H, Takashi SI. Administration of granulated BCAA, quality of life. Hepatol Res 2004;30S:42-45.

12. Maroni BJ, Steinman TI, Mitch WE. A method for estimating nitrogen intake of patients with chronic renal failure. Kidney Int 1985;27:58-65.

13. Hellerstein MK, Munro HN. Liver cirrhosis. In: Arias IM, Boyer JI, et al. editors. The liver, biology and pathobiology. 3rd ed. New York: Raven Press; 1994. p. 1169-91.

14. Cabre E, Gonzalez-Huix F, Abad-Lacruz A, et al. Effect of total enteral nutrition on the short-term outcome of severely malnourished cirrhotics. A randomized controlled trial. Gastroenterology 1990;98:715-20.

15. Sato S, Watanabe A, Muto Y, et al. for the LIV-EN Study Group. Clinical comparison of branched-chain amino acid (l-leucine, 1-isoleucine, 1-valine) granules and oral nutrition for hepatic insufficiency in patients with decompensated liver cirrhosis (LIV-EN study). Hepatol Res 2005;31:232-40.

16. Marchesini G, Bianchi G, Merli M, et al. Italian BCAA Study Group. Nutritional supplementation with branched-chain amino acids in advanced cirrhosis: a double-blind, randomized trial. Gastroenterology 2003;124:1792-801.

17. Muto Y, Sato S, Watanabe A, et al. Effects of oral branchedchain amino acid granules on event-free survival in patients with liver cirrhosis. Clin Gastroenterol Hepatol 2005;3:705-13.

18. Tsuchiya M, Sakaida I, Okamoto M. The effect of a late evening snack in patients with liver cirrhosis. Hepatol Res 2005;31: 95-103.

19. Nishiguchi S, Habu D. Effect of oral supplementation with branched-chain amino acid granules in the early stage of cirrhosis. Hepatol Res 2004;30S:36-41.

20. Suzuki K, Kato A, Iwai M. Branched-chain amino acid treatment in patients with liver cirrhosis. Hepatol Res 2004;30S:25-29. 